\title{
SEGURANÇA E SAÚdE NO TRABALHO uma questão mal compreendida
}

João CÂndido de OliveIra

\begin{abstract}
Resumo: O presente artigo analisa alguns traços da cultura ainda predominante na maioria das empresas brasileiras em relação à segurança e saúde no trabalho, que funciona ora promovendo, ora inibindo ou mesmo impedindo a implementação de ações destinadas à melhoria dos ambientes e das condições de trabalho voltadas para a promoção da segurança e saúde dos trabalhadores.

Palavras-chave: trabalho; segurança; saúde; acidentes; gestão; prevenção.
\end{abstract}

\begin{abstract}
This article analyses some features of the culture that still prevails in most Brazilian companies with respect to safety and health in the workplace. This culture alternately promotes and inhibits, or even impedes, the implementation of measures aimed at improving working environments and conditions that would enhance the safety and health of workers.

Key words: work; safety; health; accidents; management; prevention.
\end{abstract}

A companhando, há quase 30 anos, a trajetória dos programas de Segurança do Trabalho concebidos e implementados no Brasil, observou-se a falta de consistência e desenvoltura encontradas nos demais segmentos das gestões empresariais, sobretudo, no que se refere à organização da produção.

Essa impressão é fruto de vivências técnico-pedagógicas estabelecidas não só com operários em quase todos os ramos de atividades econômicas, mas também com profissionais dos serviços Especializados de Segurança e Medicina do Trabalho - SESMT, e que passam pelas médias gerências até os mais elevados escalões de empresas, em diversas regiões do País.

$\mathrm{Na}$ Fundacentro, teve-se a oportunidade de acompanhar e, na maioria das vezes, de participar, direta ou indiretamente, de grande parte das tentativas de concepção e desenvolvimento de um sistema de gestão de segurança que garantisse o trato da questão da saúde/segurança do trabalhador nas empresas, com a importância que o tema merece.

Desde a experiência frustrante com o Mapa de Riscos - que não produziu os resultados esperados -, resolveuse reunir informações, entrevistar pessoas, estudar progra- mas de segurança e saúde do trabalhador de empresas, realizando coleta sistemática de informações que se levasse a entender melhor as razões do insucesso das diversas iniciativas de criação de um sistema eficaz de gestão de segurança do trabalho, já que as existentes nunca se apresentaram como ideais. A consistência desses dados permitiu aventar algumas idéias, opiniões e conclusões, exportar a seguir.

Tentar-se-á elucidar que dificuldades interferem no sucesso dessas iniciativas, impedindo-as de romper as barreiras que as situam em segundo plano nas organizações.

O ponto de partida para essa empreitada é a definição de alguns elementos que compõem os programas de gestão de Segurança e Saúde no Trabalho - SST, nas empresas brasileiras, que constituirão o objeto dessa observação. Em função da importância, em especial para a implementação dos referidos programas, irá se tratar de três elementos que, no entender, são decisivos para o sucesso ou insucesso desses programas. Daí a necessidade de compreendê-los melhor. Trata-se, entre outros, dos três elementos básicos de qualquer programa de gestão - no caso específico, da segurança e saúde no trabalho -, que 
formam os pilares nos quais se sustentam as ações dos programas, quais sejam:

- aspectos culturais ou a forma como as partes interessadas - trabalhadores, empregadores, profissionais do ramo e governo - vislumbram e abordam a questão;

- conteúdos técnicos ou ferramentas utilizadas na identificação e controle dos riscos do trabalho;

- aspectos ligados aos resultados.

Em função do que se pretende debater no presente artigo, abordar-se-á os aspectos culturais.

\section{ASPECTOS CULTURAIS: VIESES E ACERTOS}

O que se segue objetiva levantar e analisar algumas questões, consideradas críticas, sobre o jeito de SER e de AGIR da maioria das empresas brasileiras quando o assunto é segurança e saúde no trabalho. O texto procura ainda indagar: onde se está e para aonde provavelmente se irá?

Dos diversos elementos que compõem um programa de gestão de Segurança e Saúde no Trabalho - SST, os três aqui apontados - cultura, ferramentas e objetivos -, se avaliados conforme a importância, sem dúvida, os aspectos culturais representam, de longe, o que há de mais significativo, facilitando, inibindo ou inviabilizando seu sucesso. Por mais elaborado que seja um programa de SST e por melhores que sejam as ferramentas por ele disponibilizadas para o diagnóstico e a solução dos riscos do trabalho, se não houver disposição e participação compromissada de todos os envolvidos em suas ações, especialmente do corpo gerencial da empresa, os resultados por ele produzidos serão limitados, tanto do ponto de vista quantitativo, quanto qualitativo. Pior do que os parcos resultados na correção dos riscos do trabalho é o baixo desempenho na manutenção das medidas corretivas porventura implementadas.

No entanto, em função dos traços da cultura de SST ainda predominante na maioria das empresas brasileiras, mesmo nas de grande porte, a questão da segurança e saúde no trabalho não é tratada como deveria ser, tanto por parte da empresa - na pessoa de seus prepostos -, como por parte dos trabalhadores. Esse mesmo ponto de vista pode ser observado pelas falas de trabalhadores e de prepostos dos empregadores, colhidas nas empresas por meio de questionários aplicados com essa finalidade. Os principais problemas ainda existentes na maioria das empresas, que dificultam e, em certas circunstâncias, até mes- mo inviabilizam a implementação dos programas de SST, segundo o que se pode levantar, são:

\section{Envolvimento da Alta Direção da Empresa}

Não é praxe, no Brasil, o envolvimento direto da alta direção das empresas com as questões da segurança e saúde no trabalho, salvo quando da ocorrência de acidentes graves, que, além de danos materiais, provocam ranhuras na imagem de suas empresas, atingindo-os de forma direta.

De maneira não muito diferente, seus prepostos, gerentes de todos os escalões, por não se considerarem ou não terem sido considerados pelo empregador como responsáveis diretos pela promoção da segurança e saúde no trabalho, esquivam-se, de todas as formas possíveis, de assumir o papel de gestores e responsáveis pelos programas de SST - diga-se de passagem, caros - propostos, às vezes, pelo próprio empregador.

É certo que essa postura vem declinando, sobretudo nas grandes empresas, nos últimos anos, mas não a ponto de já ter amadurecido uma nova experiência em que as questões da segurança e saúde no trabalho sejam consideradas como parte integrante do sistema produtivo, recebendo dos dirigentes das empresas o mesmo valor conferido aos itens de produção, por exemplo, e administradas por quem dispõe de poderes para intervir nos processos produtivos $-o$ corpo gerencial da empresa.

\section{Programas de SST Orientados para o Atendimento à Legislação}

Os programas de segurança e saúde no trabalho, em função da cultura dominante na maioria das empresas, são concebidos e orientados normalmente para o atendimento à legislação que dispõe sobre a matéria.

Programas fundamentados nesse princípio são, em geral, pobres e de baixo desempenho, por várias razões, mas, principalmente, porque privilegiam as situações de risco que se apresentam em franco desacordo com a Lei e que podem transformar-se em objeto de fiscalização pelo Ministério do Trabalho e Emprego ou gerar algum tipo de passivo, de natureza trabalhista ou reparatória, em detrimento de outras que podem ser muito mais nocivas à saúde do trabalhador, mas não facilmente perceptíveis. Outro aspecto negativo dos denominados programas "legalistas", 1 que combinados com a abordagem reducionista ou "minimizadora" dos riscos do trabalho reforçam seu lado negativo, é o fato de que não há cober- 
tura total de fiscalização pelo Ministério do Trabalho e Emprego em razão do reduzido número de auditores fiscais para cobrir o universo de empresas onde existem trabalhadores expostos, cotidianamente, aos riscos de acidentes e/ou de doenças do trabalho. Sem contar, o que é pior, a postura assumida por muitos gerentes de empresas, que acreditam ser o cumprimento das notificações do Ministério do Trabalho e Emprego a forma de restabelecer a conformidade legal da empresa em relação aos instrumentos legais regulamentadores da segurança e saúde do trabalhador, postura que restringe ainda mais as ações de segurança do trabalho na empresa. Essa estreiteza de visão, além de comprometer a segurança dos trabalhadores, é extremamente nociva a todos os envolvidos com os processos de trabalho na empresa por ser absolutamente equivocada. Para ser isso verdade, seria necessário ao auditor fiscal avaliar, na empresa fiscalizada, todos os itens de SST em desacordo com as normas legais vigentes e transfomá-los em notificações. A inviabilidade desse princípio não esbarra apenas em questões de natureza técnica, mas, principalmente, na missão da fiscalização.

\section{O "Ato Inseguro" como Causa Preponderante dos Acidentes do Trabalho}

Ainda em relação aos traços da cultura de SST predominante na maioria das empresas brasileiras, outro aspecto relevante que contribui negativamente para o baixo desempenho da maioria dos atuais programas de SST é o estabelecimento do nexo causal dos acidentes, tomandose como base o comportamento dos trabalhadores. Relacionar o comportamento do trabalhador com a prevenção ou a ocorrência de acidentes no trabalho - não importando se o impacto for uma intoxicação aguda ou uma fratura óssea ou coisa do mesmo gênero - não é tarefa difícil nem mesmo para os leigos no assunto, quanto mais para quem milita no ramo da promoção da segurança e saúde do trabalhador. Tal fato, todavia, não ocorre quando se pretende elucidar os determinantes do comportamento dos indivíduos, o que, em última instância, é o que interessa a quem lida com a gestão da segurança no trabalho.

É sabido que quantidade apreciável dos acidentes do trabalho ocorridos, no Brasil ou em qualquer parte do mundo, origina-se no comportamento das vítimas. Quanto a isso, não há nenhuma dúvida; o que é mal interpretado ou às vezes compreendido erroneamente, de propósito, é por que as pessoas se expõem, de maneira passiva, sem os devidos cuidados, a uma condição de risco que possa lesá-las ou matá-las. Afora os equívocos ou as intenções que os orientam, a alteração do comportamento do trabalhador em relação ao que se qualifica como o corretamente esperado não deixa de ser um sério agravante na exposição aos riscos ocupacionais, sobretudo, quando eles não são tão conhecidos, qualificados e avaliados corretamente. $\mathrm{E}$, pior, controlados de modo inadequado ou nem mesmo controlados.

A incidência de acidentes relacionados ao cometimento de erros no trabalho não é pequena no universo dos acidentes registrados e estudados. Milhares de trabalhadores morrem ou mutilam-se todos os anos no Brasil e em outras partes do mundo, em decorrência de acidentes do trabalho cujas causas vão desde a precariedade das condições físicas do ambiente onde o trabalho se realiza, às diversas formas de distorções em sua forma de organização até os comportamentos inadequados dos trabalhadores, traduzidos em erros comprometedores na execução de suas tarefas. A inclusão do comportamento dos trabalhadores no conjunto dos fatores causais de acidentes do trabalho, quando cabível, de forma alguma significa debitar aos trabalhadores acidentados a culpa pelos acidentes e, consequientemente, pelos danos deles decorrentes, incluindo invalidez e morte.

$\mathrm{Na}$ arte de prevenir acidentes, o comportamento do trabalhador, como foi expresso na ação do acidente, ainda que tenha sido a causa preponderante, é de importância secundária, às vezes até irrelevante. O que deve ser levado em conta - e, por todos os meios possíveis, valorizados e cuidadosamente estudados - são os determinantes do comportamento, ou seja, o que o motivou: o que havia de errado no ambiente, nas relações de trabalho e ainda na vida do trabalhador que interferiam, direta ou indiretamente, no relacionamento dele com o todo de seu trabalho, definindo posturas traduzidas em atitudes corretas ou equivocadas. A figura do "Ato Inseguro" - que tanto serviu e continua, em alguns ambientes, servindo para responsabilizar e até mesmo para culpar trabalhadores pelos acidentes sofridos - não serviu para outra coisa senão para ocultar e/ou mascarar, em algumas empresas, sinais de agravos à saúde do trabalhador e, da mesma forma, distorções na organização do trabalho do que propriamente às finalidades para as quais se propunha, que era estabelecer nexo entre os acidentes ocorridos e suas reais causas. O questionamento em relação à figura do "Ato Inseguro" não se refere ao comportamento do trabalhador, expresso no cometimento de erros no trabalho, mas à parcialidade com que foi utilizado na definição causal dos 
acidentes. O erro na execução do trabalho, embora indesejável, é passível de ocorrer, e todos, indistintamente, nele podem incorrer. Não é, por conseguinte, o erro, como erro, que interessa a quem lida, com espírito construtivo, com a prevenção de acidentes, mas as causas do erro, não importando sua clarividência - se visíveis ou ocultas, se imediatas ou remotas.

A abordagem da segurança do trabalho valendo-se do raciocínio de que o trabalhador erra ao executar suas tarefas porque é displicente, indisciplinado, negligente, imperito ou simplesmente imprudente - princípios nos quais se fundamentam as teses do "Ato Inseguro" - é tão nociva à gestão da segurança no trabalho quanto o é a crença de que o trabalhador, por sua conta e risco, nunca erra. E, quando erra, é porque foi induzido ao erro por motivos totalmente alheios não apenas a sua condição de trabalhador, mas também de humano. Ambas as linhas de raciocínio falham e em nada contribuem para a segurança no trabalho porque, de um lado, constrói-se a idéia de um trabalhador anárquico, irresponsável e indisciplinado em relação ao cumprimento de normas de trabalho - normas, na maioria das vezes, elaboradas por quem não está diretamente envolvido com os processos de trabalho e, por desconhecimento, não define o que deve ser rígido ou flexibilizado nas normas. Daí a explicação da "desobediência", parcial ou total, do trabalhador a seu cumprimento. De outro lado, retrata-se um trabalhador, em todos os sentidos, duplamente vitimado. Vitimado em relação aos impactos do acidente ou da doença, o que é absolutamente verdadeiro, e vitimado em relação a suas causas, nas quais, ele, na condição de cidadão e de sujeito, com sua cultura e seu jeito de ser em todas as relações de trabalho, parece não existir. E, se existe, é desprovido de autodeterminação quanto a seus atos, ainda que na defesa da saúde e da vida. Não há dúvida que qualquer julgamento, premeditado ou não, acerca da causalidade acidentária, que tome como base os extremos dos dois pontos de vista aqui mencionados, é suscetível de falhas, uma vez que desvia o ponto de atenção e de análise das condições ambientais nas quais o trabalho realiza-se e dos elementos fundamentais de sua organização.

\section{Comportamento do Trabalhador e sua Relação com a Organização do Trabalho}

É certo que o trabalhador age, de um lado, orientado pelos ditames da empresa; de outro, em função das condições de trabalho, mas também, e principalmente, pela consciência da realidade na qual ele está inserido. Daí não ser correto supor que o comportamento do trabalhador, decorrente ou não das circunstâncias já mencionadas, não contribui para a ocorrência dos acidentes no trabalho isso entendendo que o que se pretende com a investigação não é culpar o trabalhador pelo acidente, mas, pura e simplesmente, estabelecer nexo entre o acidente e seus determinantes causais.

Um modelo de gestão de segurança do trabalho que permite relacionar a ocorrência de acidentes do trabalho ao comportamento do trabalhador, definindo-o como displicente, imperito, negligente e/ou imprudente, na definição causal dos acidentes, sem considerar as condições físicas do ambiente laboral e, principalmente, seus elementos determinantes na organização formal ou informal, certamente, estará tratando a questão da SST de forma superficial, parcial e, o que é pior, às vezes, inconseqüente.

Embora, por essa via, a análise pode privilegiar o comportamento da vítima, desvinculado dos fatores que o tenham determinado, em detrimento da investigação científica que procura, isenta de parcialidade, desvendar e correlacionar os determinantes causais dos acidentes.

A definição da causa dos acidentes do trabalho pela via do "Ato Inseguro" não peca apenas por privilegiar o comportamento do trabalhador como causa preponderante dos acidentes do trabalho, em detrimento da qualidade dos ambientes e de sua organização, mas, sobretudo, por supor que os erros cometidos pelo trabalhador na execução de suas tarefas derivam-se, pura e simplesmente, de suas próprias limitações, não guardando, por isso, qualquer relação com a forma de ser e de agir da empresa. Essa estreiteza de imaginação ou imaginação intencional, combinada com o extremo de supor que o comportamento do trabalhador, não importando as razões que o determinem, não deve ser abordado como causa de acidente porque ele, em todos os sentidos, deve ser visto e tratado como vítima - não apenas empobrece qualquer iniciativa na área de gestão de SST, mas concorre para reforçar as teses que sustentam não ser a segurança do trabalho problema de gestão da produção, mas problema relacionado à qualidade da mão-de-obra da empresa. Daí a preocupação em se reforçarem as práticas de treinamento em prevenção de acidentes, desvinculadas dos processos produtivos, acreditando que a capacitação do trabalhador para fazer segurança seja a solução mais produtiva na prevenção de acidentes, o que nem sempre ocorre. $O$ treinamento em prevenção de acidentes produz excelentes resultados, não há dúvidas, quando associado à melhoria contínua dos ambientes e da organização do trabalho. 
Outro aspecto negativo na abordagem do acidente do trabalho com base no comportamento do trabalhador, na visão do "Ato Inseguro", reside no equívoco de se supor que o trabalhador comete erros no trabalho simplesmente porque, em determinado momento, decide, por conta própria, como se comportar no trabalho, improvisando condições alternativas para a realização das tarefas, ignorando procedimentos normativos previamente definidos para o mesmo - procedimento ou prática padrão. Afirmar que o trabalhador decide por conta própria como se comportar em relação às normas que orientam o trabalho, sem considerar as variáveis que o envolve, revela não apenas uma inversão de papéis, mas, sobretudo, uma demonstração clara da forma como o trabalho é organizado naquele ambiente, bem como as incongruências de seus sistemas de controle. A organização da produção e o que dela decorre: fazer o quê, por quê, como, onde e especialmente por quem, sempre foi tarefa indelegável da empresa e não dos trabalhadores. Não se concebe que o trabalhador, em nenhuma empresa brasileira, em face da cultura do trabalho ainda predominante no Brasil, disponha de poderes para decidir, individualmente, como deve comportar-se no trabalho, independentemente das determinações normativas impostas pela empresa. O que se afigura como mais provável, nesse particular, são as falhas de controle que a empresa exerce sobre o trabalho em decorrência de deficiências em seu sistema de organização, em especial em relação à organização formal do trabalho.

\section{Inserção dos Trabalhadores nos Programas: Treinamento}

Ainda em relação aos aspectos culturais vinculados à segurança e saúde do trabalhador, ao longo dos anos em que se lidou com essa questão, constatou-se algo, de certa forma, paradoxal, porém verdadeiro e importante: tão nefastas quanto as doenças e os acidentes do trabalho são as formas escolhidas por algumas empresas para com eles lidar. O enfrentamento dessa questão, por sua complexidade e multicausalidade, não passa apenas pelo treinamento específico de trabalhadores para fazer segurança, independentemente das condições físicas onde o trabalho se realiza. Acredita-se até que treinar trabalhadores para o estrito cumprimento de normas - em ambientes agressivos, desfavoráveis à vida, onde a organização do trabalho em nada favorece o seu exercício correto - sem lhes oferecer as condições necessárias e abertura para discutir, ponderar e propor medidas de melhorias, tanto no ambiente quanto na organização do trabalho, é exacerbar o estado de angústia que caracteriza a exposição, consciente, a riscos potencialmente capazes de gerar danos à saúde. Isso porque, uma coisa é expor-se a uma situação de risco à saúde e/ou à integridade física, sem saber o que isso significa; outra, bem diferente, é ter consciência do problema e ter que a ele expor-se sem condições para agir. Nesse caso, o dano não se restringe apenas àquele provocado pelo risco em questão, mas, também, pelo sofrimento de natureza mental de não poder proteger-se. Oferecer essa condição ao trabalhador, na expectativa de que ela seja um caminho alternativo para a solução do problema acidentário, além de não representar solução alguma, aprofunda ainda mais o fosso que separa os propósitos da empresa em relação ao tema do engajamento voluntarioso e compromissado dos trabalhadores.

Nada mais danoso a qualquer programa de gestão de SST do que o constrangimento sofrido por trabalhador submetido a treinamento específico de segurança promovido pela própria empresa, mas que, ao tentar praticar as lições aprendidas, é impedido de fazê-lo, ora por decisão de suas chefias imediatas, sem justificativas convincentes para tal, ora por impedimento das próprias condições de trabalho. No caso da segunda hipótese, o conflito está intimamente relacionado ao fato de o conteúdo do treinamento não ter considerado as peculiaridades do ambiente e do trabalho. Em todos os sentidos, a ocorrência desse fato pode ser debitada à desvinculação da SST dos processos produtivos e da própria organização do trabalho. Iguais a isso, ou pior, são determinadas posturas assumidas, de forma contundente, por alguns gerentes ao reivindicarem direitos legalmente instituídos para proteger trabalhadores, habitual e permanentemente, expostos a agentes nocivos à saúde, como os adicionais de insalubridade e periculosidade. E, da mesma forma, a aposentadoria especial.

\section{Paradoxos da SST: Adicionais de Insalubridade e Aposentadoria Especial}

Quanto à última afirmativa, não nos parece que o gerente não deva reivindicar, por razões éticas, direitos decorrentes da exposição a riscos do trabalho ou a redução do tempo para aposentadoria, quando cabíveis, mesmo porque a concessão desses "benefícios" depende da aplicação da legislação pertinente. A questão é que essa postura, principalmente advinda dos gerentes, reforça, ainda mais, as teses que vinculam a segurança do trabalho à 
monetarização da saúde dos trabalhadores por meio de pagamento de adicionais de insalubridade, em detrimento da melhoria das condições de trabalho.

Quanto a essa afirmação, testemunhou-se diversas iniciativas, por parte de algumas empresas, cujo propósito era a eliminação de determinadas condições insalubres passíveis disso, seguidas da supressão do adicional de insalubridade constante da folha de pagamento dos trabalhadores e por eles terminantemente rejeitadas. É imprescindível para quem deseja, de modo imparcial, aprofundar no assunto, questionar os motivos que ainda direcionam uma parcela considerável de trabalhadores a tal posicionamento. O que foi possível observar, por meio de pesquisas realizadas em diversas empresas de ramos de atividades diferentes, é que, nas categorias de trabalhadores em que o salário é por demais reduzido, os trabalhadores não abrem mão do referido adicional, por ser ele parte considerável de seus ganhos - como o são, da mesma forma, as horas extras. Já nas categorias em que os salários são mais elevados, o pleito pelo adicional de insalubridade associa-se à idéia de que por meio dele se assegura, na Previdência Social, a obtenção da aposentadoria especial.

Quanto ao primeiro posicionamento, a despeito da desumanidade que o caracteriza, embora inaceitável, é perfeitamente compreensível; já o segundo trata-se de desinformação, uma vez que a aposentadoria especial, hoje, depende da efetiva comprovação técnica de que a condição de trabalho é prejudicial à saúde do trabalhador, seguida do pagamento de seu respectivo custeio. De qualquer forma, independentemente das razões alegadas, a monetarização da saúde não deveria, em hipótese alguma, por razões humanas e morais, ser objeto de negociações que não objetivassem sua supressão. Evidentemente, essa supressão não se restringe à figura jurídica da insalubridade, mas, sobretudo, às condições de trabalho que a ensejam.

Todavia, a opinião é que, entre se expor a uma condição agressiva à saúde sem nada receber e tendo como única alternativa a ela se expor, o melhor será fazê-lo; no entanto, por isso recebendo.

Entre os diversos aspectos negativos da cultura brasileira relacionada à segurança do trabalho, a monetarização da saúde - pelo nefasto adicional de insalubridade - e a redução do tempo de serviço para a aposentadoria, sem o devido custeio feito pelas empresas, ${ }^{2}$ representam o que há de pior. Convencer os trabalhadores de que melhor do que quaisquer ganhos monetários decorrentes da exposi- ção aos riscos no trabalho são as medidas saneadoras desses riscos é tarefa difícil, por vários motivos, mas, principalmente pelo fato de os trabalhadores, ao longo do tempo, terem associado, de forma errônea, a concessão da aposentadoria especial à percepção do adicional de insalubridade.

\section{Ordenamento Formal do Trabalho e os Conflitos de Poder}

Outro aspecto importante, fruto dos traços da cultura ainda predominante nas empresas, que interfere, de maneira negativa, no desempenho da gestão da segurança e saúde do trabalhador, é o dualismo vivenciado cotidianamente pelos trabalhadores no cumprimento do ordenamento formal do trabalho. $\mathrm{O}$ fosso que ainda separa o discurso formal do trabalho (normas escritas) da diversidade de formas práticas - nem sempre conforme o que está escrito - de realização das tarefas, por parte dos trabalhadores, relaciona-se, possivelmente, a três fatores distintos:

- condições de trabalho nem sempre compatíveis com as exigências contidas nos procedimentos escritos;

- deficiência na capacitação técnica dos trabalhadores para a correta execução das tarefas conforme prescrições normativas;

- duplicidade de orientação sobre como realizar as tarefas.

Dos três fatores enumerados, sem nenhuma dúvida, a duplicidade de orientação é a que mais confunde os trabalhadores no exercício de seu trabalho. A maioria dos trabalhadores brasileiros aprendeu a trabalhar seguindo orientações orais - ordens - de suas chefias imediatas. Poucas eram as ordens escritas passadas aos trabalhadores, o que difere da atualidade, em que praticamente todas as atividades são normalizadas, seguem prescrições sobretudo contidas nos programas de qualidade. No dia-a-dia das empresas, o que se verifica, na prática, porém, é uma espécie de rito de passagem das formas antigas de comando, orientadas por meio da fala imperativa, dos encarregados para uma comunicação formal, conformada por normas de procedimentos escritos. Com isso, o gerente que exercia um papel caracteristicamente de mando transforma-se, aos poucos, numa espécie de facilitador.

O problema é que essa experiência é recente demais e tanto os gerentes quanto os trabalhadores ainda não se adaptaram suficientemente a ela a ponto de fazê-la funcionar sem conflitos, em especial, nas relações de comando. 
Outro fator relevante que não pode ser desprezado na compreensão do fenômeno (teoria e prática), em razão de sua importância, é a dificuldade de estabelecerem parâmetros entre a realização de uma atividade prática, por um ou mais trabalhadores, reproduzindo experiências acumuladas ao longo do tempo, sem orientação formal, e a realização da mesma atividade conforme prescrições formalizadas. Isso porque, uma coisa é a realização de uma atividade de maneira informal, em que a aprendizagem dáse por experimentações, ou seja, por tentativas que envolvem erros e acertos; outra coisa, muito diferente, é a realização da mesma atividade segundo prescrições formais. Em decorrência disso, verificam-se ainda, e com razoável frequiência, conflitos entre trabalhadores e supervisores no ordenamento dos trabalhos. Há momentos em que trabalhadores defrontam-se, sem saber como agir, com conflitos surgidos entre eles e suas chefias imediatas em relação a que ou a quem obedecer, seguir os procedimentos escritos determinados pela própria empresa, ou acatar as ordens de suas respectivas chefias - ordens que, muitas vezes, passam ao largo das determinações formais.

As origens desses conflitos estão nas dificuldades de transformarem, em curto prazo, as experiências construídas e vivenciadas ao longo de gerações em relações formalizadas, em que prevalece não o que se verbaliza oralmente, mas o que está escrito.

\section{Postura das Chefias em Relação à SST}

Como ilustração das dificuldades de lidar com questões de segurança e saúde dos trabalhadores nas empresas, com base na visão de seus gestores, aqui são retratadas algumas falas recolhidas por intermédio de pesquisas em seis grandes empresas mineiras, dos ramos de metalurgia, siderurgia, mineração e serviços, realizadas nos anos de 1995 e 1996. Ressalte-se que os mesmos itens abordados na época foram objeto de estudos no ano de 2001 e os resultados obtidos, comparados à primeira pesquisa, não sofreram alterações substanciais, como se imaginava que acontecesse em face da movimentação, ocorrida no mesmo período, em decorrência da implantação dos programas de qualidade e meio ambiente apoiados nas séries ISO 9000 e 14000.

Tanto a primeira quanto a segunda pesquisa foram elaboradas com 30 perguntas, seguidas de seis alternativas de respostas que afirmaram ou negavam o que estava sendo perguntado, e o entrevistado pôde escolher até três alternativas de respostas, com ordem crescente de afirmação ou de negação.

\section{RESUMO DA FALA DOS GERENTES: O QUE PENSAM E O QUE FAZEM}

Entre os trinta itens abordados nas duas pesquisas, elegeu-se dez para apoiar os comentários que serão feitos a seguir.

Foi tomado como referência apenas os itens que obtiveram mais de $60 \%$ de respostas afirmativas entre os 312 gerentes entrevistados. Denominou-se gerentes todos os ocupantes de cargo que tivessem, direta ou indiretamente, a função de mando e/ou de facilitador do trabalho de outrem, como: gerente técnico, supervisor, encarregado e líder de equipes.

Os itens são os seguintes:

- Os gerentes que trabalham de forma direta com riscos potencialmente capazes de gerar danos à saúde dos trabalhadores não dispõem do conhecimento necessário para com eles lidar de modo adequado.

- Os gerentes que convivem com riscos, mesmo sabendo de sua existência, não assumem o compromisso de corrigi-los pelo simples fato de ser essa uma tarefa de competência do SESMT.

- Os gerentes que lidam com os riscos podem saber de sua existência, mas não se esforçam para corrigi-los porque suas chefias superiores não lhes dão apoio para as ações necessárias.

- A situação de risco é mantida porque sua existência não atrapalha; se atrapalha, não impede a realização do trabalho.

- A exposição, por longo tempo, a determinada condição de risco, sem o controle devido, termina induzindo as pessoas a enxergá-la como normal e aceitável.

- A situação de risco é mantida porque ninguém toma qualquer providência para corrigi-la.

- A situação de risco é mantida porque todas as preocupações e recursos são voltados prioritariamente para o atendimento às finalidades do negócio.

- A situação de risco é mantida porque as gerências das áreas alegam não dispor de recursos (orçamentários e de mão-de-obra) para sua solução.

- A situação de risco é mantida em razão da descrença das pessoas com ela envolvidas, por falta de respostas às inúmeras solicitações de correção.

- A situação de risco é mantida e, às vezes, agrava-se em função da indefinição do trabalhador em relação a quê ou a quem obedecer - se aos procedimentos escritos ou às ordens dos supervisores. 
Como contribuição ao tema e em contrapartida às impressões colhidas dos gerentes, foram enumeradas - conforme a seguir - 20 considerações extraídas da fala de 1.372 trabalhadores, de cinco ramos de atividades econômicas diferentes, por ocasião da última pesquisa. Ressalte-se que todas as afirmações aqui resumidas foram recolhidas do conjunto de respostas que obtiveram mais de $50 \%$ de afirmação. As constatações são as que se seguem: - A segurança no trabalho é mais importante no discurso da direção da empresa do que propriamente nas áreas onde ela deveria, de fato, ser realizada.

- A Segurança do Trabalho, na prática, só adquire importância nos momentos de crise (quando ocorre acidente grave que pode comprometer principalmente a imagem da empresa).

- O fosso que separa o discurso (SST como valor) da prática (o que efetivamente é feito) constitui o mais importante obstáculo no desenvolvimento das ações de SST na empresa.

- A forma errada como sempre se trabalhou, acreditando que se trabalhava correto, dificulta e/ou inviabiliza, a curto prazo, a prática de procedimentos corretos.

- As tarefas são descritas (Tarefa Padrão - TP ou Procedimento Operacional Padrão - POP) com base no que é desejável, no que às vezes é necessário. Não são consideradas, porém, pelo menos como deveria, as dificuldades que os trabalhadores encontram na execução das tarefas conforme prescritas.

- O treinamento para o cumprimento das TPs é, em geral, inadequado, porque não leva - ou pouco leva - em conta a realidade do ambiente de trabalho e as dificuldades vivenciadas pelos trabalhadores para o pronto atendimento aos padrões estabelecidos.

- A empresa expressa por meio das TPs o que ela deseja. Na prática, as condições de trabalho oferecidas ao trabalhador dificultam ou não lhe permitem o cumprimento do que está prescrito na tarefa.

- O trabalhador sabe que o que é mais importante para a empresa não é como o trabalho está sendo executado embora o correto fosse o desejável, ou seja, o que está escrito nos procedimentos - mas o resultado dele advindo (a produção).

- O trabalhador não é cobrado pela forma como desenvolve seu trabalho, mas pelos resultados. Disso resulta o fato de os supervisores não verem ou fingirem que não vêem o cometimento de "erros" na execução da tarefa.
- Supervisão ambígua. O supervisor é cônscio do trabalho a ser desenvolvido (consta nos procedimentos). Sabe operacionalizar conforme prescrito; no entanto, facultalhe fazer com base nas experiências consolidadas ao longo do tempo, porque compreende que o mais importante para a empresa não é como fazer, mas fazer (a produção é prioridade).

- Ambigüidade entre o que se determina e o que é executável. O trabalhador encontra dificuldade enorme em definir ao que ou a quem obedecer - se a prescrição das tarefas ou a fala do supervisor.

- O trabalhador, às vezes, prefere, de forma silenciosa, correr o risco oferecido pela atividade a correr o risco de ser mal-entendido, taxado de medroso e frouxo pelos colegas ou mesmo pela chefia em caso de reclamação ou de recusa ao trabalho.

- É consenso entre trabalhadores e supervisores que, se o risco de determinada tarefa é considerado leve ou moderado, é preferível a ele expor-se para agilizar a execução da tarefa do que executar conforme o prescrito, gastandose mais tempo em sua execução.

- O trabalhador, embora sabendo (consta nos procedimentos) que pode recusar-se a executar tarefa perigosa sem a prevenção devida, prefere executá-la em desobediência à norma pelo fato de desconhecer qual seria a reação da empresa (sua chefia) em face de sua recusa.

- A avaliação inadequada do risco (minimizar ou exagerar) dificulta a tomada de decisões corretas em relação a seu controle, especialmente por parte das chefias.

- Por não ser a segurança parte integrante das atividades produtivas, quem cria ou mantém a situação de risco (chefias das áreas operacionais) não se sente responsável por sua correção.

- Por ser a produção prioritária, seus responsáveis sempre alegam não dispor de recursos para a correção de situações de risco, ainda que o recurso seja apenas o comprometimento.

- A segurança do trabalho é exigida pelas chefias, desde que não interfira nos cronogramas de produção.

- Grande parte das situações de riscos poderia ser resolvida se houvesse interesse e comprometimento da chefias em resolvê-las.

- Uma dificuldade importante do trabalhador no enfrentamento dos riscos do trabalho reside nas frequientes alterações de funções para atendimento às demandas de trabalho, por causa do reduzido número de trabalhadores. 
A definição de fatores culturais como obstáculos ao avanço das questões da saúde e segurança no trabalho nas empresas constitui problema não apenas nos países onde as relações entre capital e trabalho ainda se encontram em estágios atrasados. Mesmo nas economias altamente desenvolvidas, o problema existe e manifesta-se, em alguns pontos, tal como ocorre no Brasil e em outros países em vias de desenvolvimento.

Como exemplo, vale apresentar uma relação de 15 itens, elaborada por Hale e Glendon (1997), com a qual o leitor poderá fazer uma comparação e elaborar suas conclusões: - limitação de recursos para remoção do perigo;

- ultrapassagem dos limites das tarefas ou atribuições dos profissionais;

- aceitação dos perigos como inevitáveis;

- influência do clima social;

- tradição na indústria;

- falta de competência técnica para remoção do perigo;

- incompatibilidade de demandas (produção, custos, qualidade versus segurança);

- dependência do trabalhador;

- falta de autoridade para fazer alguma coisa;

- situações contingentes;

- gestão ou gerenciamento de fatores do sistema de segurança;

- sobrecarga de tarefa;

- práticas, políticas e regras das empresas;

- falta de informação (quebra de comunicação);

- inexistência de obrigação legal.

Comparando os itens aqui apresentados e os dos pesquisadores holandeses, Hale e Glendon, verificou-se que há enorme semelhança entre eles. A justificativa da escassez de recursos para solucionar problemas pertinentes à segurança do trabalho não relaciona-se propriamente à sua falta, mas à importância que se dá ao emprego. Hale e Glendon (1997) verificaram que tal alegação para corrigir situações de risco no trabalho não procedia apenas das médias e pequenas empresas holandesas, mas também das grandes, com inclusão das estatais. E mais, que o fenômeno não se verificava apenas na Holanda, mas em todos os países da União Européia por eles visitados. Outro item da listagem holandesa que despertou atenção foi o que se refere à falta de autoridade para decidir sobre a intervenção no ambiente de trabalho, isto é, na corre- ção dos riscos. Contudo, a pesquisa de Hale e Glendon (1997) não define de quem é a falta de poder para intervir nas condições de trabalho, se dos trabalhadores ou dos gerentes das áreas de riscos. Outro fator importante não elucidado pelos autores é o que se refere aos aspectos de gerenciamento da segurança do trabalho. Como esse gerenciamento é conduzido, se separado dos processos produtivos, como é o caso brasileiro, ou se integrado a todo o complexo produtivo e de responsabilidade das chefias das áreas.

De acordo com o que foi visto até aqui, pode-se afirmar, sem receio de cometer injustiças, que o juízo que os trabalhadores fazem dos aspectos de sua segurança e saúde no trabalho relaciona-se, intimamente, aos conteúdos e à maturidade dos programas de segurança e saúde desenvolvidos nas empresas nas quais trabalham.

Nas empresas em que os programas de SST são concebidos e implementados para o estrito cumprimento das exigências legais sobre a matéria, a representatividade dos trabalhadores em relação a eles certamente se limitará ao que lhes é exigido por parte da empresa.

É pouco provável que os trabalhadores de uma empresa que não vislumbra a segurança do trabalho como valor agregado a seu negócio, que não apresentam seus programas de SST alinhados ao sistema produtivo - promovendo a melhoria contínua das condições e procedimentos de trabalho e investindo pesadamente na educação dos trabalhadores e de seu corpo gerencial para o correto exercício do trabalho - possam enxergar a segurança do trabalho como valor que se equipara a outros itens relacionados diretamente ao negócio, como produção, por exemplo.

As experiências demonstram que a participação dos trabalhadores nos programas de SST vincula-se intimamente à cultura da empresa relacionada com o tema e sobretudo ao conjunto de ações que ela desenvolve, em especial na área de educação, para incorporá-los aos seus programas. Nas empresas em que os programas de segurança desvinculam-se das atividades produtivas, organizados e implementados pelas equipes de segurança (o SESMT), é comum trabalhadores associarem as ações de segurança do trabalho com o vivenciado no cotidiano como, por exemplo, uso de equipamentos de proteção individual (EPI) e realização de exames médicos, principalmente os periódicos. Fora isso, restam as atividades da Comissão Interna de Prevenção de Acidentes - CIPA, que também são de seu conhecimento. Num ambiente dessa natureza, dificilmente os trabalhadores associam as ações 
de segurança à promoção da qualidade de vida ou algo que possa melhorar o seu relacionamento com o próprio trabalho, diferentemente das empresas em que os programas de segurança do trabalho são abordados como parte integrante dos processos produtivos, e as ações de segurança são concebidas e implementadas como parte integrante do próprio negócio da empresa.

A importância da adoção de programas dessa natureza, entre outras vantagens, está no ganho de não ser preciso desenvolver ações em duplicidade para abordar o mesmo conteúdo, que são os aspectos produtivos. Isso sem contar com uma vantagem maior: a possibilidade de convencer os trabalhadores de que para fazer segurança não é necessário desenvolver ações específicas para tal, basta incluir essa preocupação nos procedimentos de trabalho e transformá-la em ações concretas que possam ser avaliadas e medidas.

\section{NOTAS}

1. Legalista, entre aspas, refere-se aos desvios, na prática, do real significado da palavra. Algumas empresas, e não são poucas, "maquiam” seus ambientes de trabalho com Mapas de Risco, feitos normalmente por empresas especializadas em Segurança e Saúde no Trabalho - sem a participação dos gerentes das áreas produtivas e dos trabalhadores - com o objetivo puro e simples de "parecer cumprir" a Lei. Paradoxalmente, por essa via, gastam mais do que se controlassem efetivamente seus ambientes de trabalho. Por esse expediente, a empresa continua não protegendo seus trabalhadores e abrindo espaços ao acúmulo de passivos.

2. A partir de dezembro de 1999, a Previdência Social passou a exigir das empresas pagamento adicional, por redução de tempo de trabalho, para concessão da aposentadoria especial.

\section{REFERÊNCIAS BIBLIOGRÁFICAS}

DUARTE, E.F. Programa cinco minutos diários de segurança, saúde ocupacional e meio ambiente. Belo Horizonte: Ergo, 1999.

GRIMALDI, J.V.; SIMONDS, R.H. Safety management. Homewood. Richard D. Irwin, 1975. 694 p.

HALE, A.R.; GLENDON, A.I. Individual behaviour in the control of danger. Amsterdam: Elesevier, 1997. In: ALMEIDA, I.M. Construindo a culpa e evitando a prevenção. Tese Doutorado (versão preliminar). São Paulo, USP, 2000

MBR. Aperfeiçoamento estratégico dos programas e sistemas de segurança. Belo Horizonte: Athur D. Litle, 1993.

OLEA, M.A. Introdução ao direito do trabalho. 4. ed. São Paulo: LTR 1974. $294 \mathrm{p}$.

OLIVEIRA, J.C. Gestão de riscos no trabalho: uma proposta alternativa. Minas Gerais, Fundacentro/CEMG, 1999.

Sistema de gestão. Revista Proteção, Novo Hamburgo, MPF, ano 14, n.112, p.52-59, abr. 2001.

. Sistema de gestão. Revista Proteção, Novo Hamburgo, MPF, ano 14, n.113, p.52-61, maio 2001.

. Sistema de gestão. Revista Proteção, Novo Hamburgo, MPF, ano 14, n.114, p.54-63, maio 2001.

Gestão de segurança e saúde do trabalhador - uma questão para reflexão. In: IRT, FUNDACENTRO. Novos Desafios em Saúde e Segurança no Trabalho. Belo Horizonte: PUC/Minas, 2001.

OLIVEIRA, S.G. Proteção jurídica à saúde do trabalhador. São Paulo. 3. ed. São Paulo: LTr, 2002.

SARTORI, G. A política. Distrito Federal: UnB, 1997. 257 p.

STELMAM, G. Trabalho e saúde na indústria. São Paulo: Edusp, 1978. 3v.

João Cândido de Oliveira: Tecnologista da Fundacentro - MG e Professor da Faculdade de Ciências Médicas de Minas Gerais. 